\title{
Return of Chum Salmon and Water Quality and Ecology in the Rivers Connected with the Eastern Coast of Korea
}

\author{
Chung Il Lee ${ }^{1}$, Hyun Je Park ${ }^{1}$, Jong-Won Park ${ }^{1}$, Seong- Ik Hong ${ }^{2}$, Tae Hee Park ${ }^{1}$, Hae Kun Jung ${ }^{1}$, Joo Myun \\ Park $^{1}$, and Ju Kyoung Kim ${ }^{3}$ \\ ${ }^{1}$ Department of Marine Bioscience, Gangneutn-Wonju National University, Gangwon, Korea \\ ${ }^{2}$ Bada Ecology Institue, Gangwon, Korea \\ ${ }^{3}$ Inland Life Resources Center, Korea Fisheries Resources Agency, Gangwon, Korea
}

Keywords: returning rate, river condition, trophic level

Chum salmon, Oncorhynchus keta, is major species which returns to rivers in Korea, and about $98 \%$ of chum salmon return to rivers along the eastern coast of Korea. The returning rate of chum salmon in Korea is generally proportional to latitude, release amount, water quality, and ecological status in rivers which are important factors affecting the return of the species to the rivers. In this study, water quality and biological characteristics were monitored in five rivers along the eastern coast of Korea from the Taehwa River, the southernmost river to the Myeongpa River, the northernmost river.

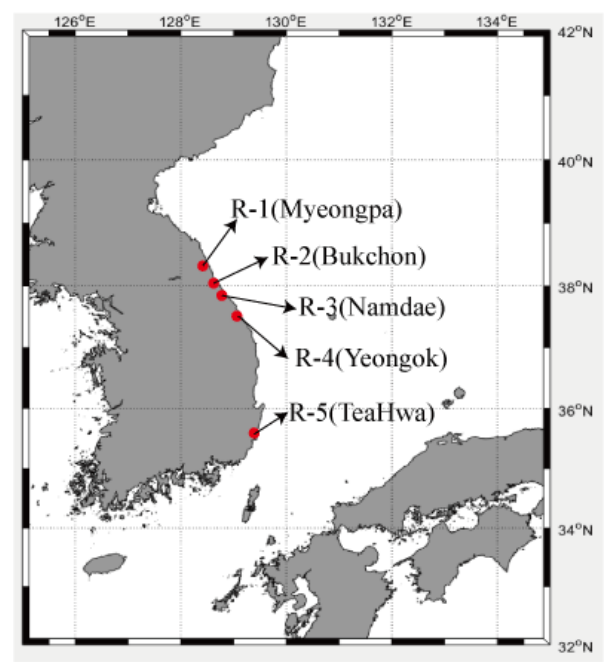

Fig. 1. The major natal rivers of chum salmon in Korea.

Table 1. The velocity and discharge rates for each river.

\begin{tabular}{cccccc}
\hline & Myeongpa & Bukchon & Namdaecheon & Yeongok & Taehwa \\
\hline Velocity $(\mathrm{m} / \mathrm{s})$ & 1.16 & 0.35 & 0.24 & 0.21 & 0.049 \\
Discharge $\left(\mathrm{m}^{3} / \mathrm{s}\right)$ & 2.59 & 9.09 & 21.15 & 5.18 & 5.96 \\
\hline
\end{tabular}

Table 2. The water temperature, salinity, and dissolved oxygen of each river in June and August 2017.

\begin{tabular}{lccccc}
\hline & Myeongpa & Bukchon & Namdaecheon & Yeongok & Taehwa \\
\hline Tem. $\left({ }^{\circ} \mathrm{C}\right)$ & 18.57 & 20.34 & 21.8 & 24.36 & 25.67 \\
Sal. $(\mathrm{psu})$ & 0.05 & 0.05 & 1.4 & 2.17 & 3.3 \\
Do. $(\mathrm{ml} / \mathrm{l})$ & 6.97 & 7.15 & 7.17 & 7.96 & 7.79 \\
\hline
\end{tabular}

The five rivers (i.e., the Taehwa, Yeongok, Namdaecheon, Bukchon, and Myeongpa from south to north of the eastern coast) (Fig. 1), have distinctly different environmental conditions. The latter four rivers are surrounded by natural forests, but the Taehwa River flows through a large industrial and urban area before it reaches the sea. Thus, it is assumed that the Taehwa River has poor water quality due to human-induced influences, while water quality in the other rivers are improved with the latitude and geographical features. The water temperature and dissolved oxygen (DO) have decreased with increasing latitude (Table 1). DO in each river has a range from 6.97 to 
7.96 (Table 1), and the highest value was recorded in Teahwa and Yeongok (Table 2). The highest water flow such as velocity and discharge was recorded in the Namdaecheon $\left(21.2 \mathrm{~m}^{3} / \mathrm{s}\right)$ (Table 2). In the results of the stable isotope analysis, $\delta^{13} \mathrm{C}$ values of suspended particulate organic matter (SPOM) were about $-30 \%$ in all sampling sites, suggesting a higher contribution of terrestrial organic matter. For $\delta^{15} \mathrm{~N}$ values, SPOM were generally higher in August than those in June (Fig. 2). The consumers in Myoungpa, Buk, and Yeongok streams showed wide ranges in $\delta^{13} \mathrm{C}$ values (-28.0\%o to $-19.6 \%$ in June; $-29.3 \%$ to $-22.0 \%$ in August), suggesting a higher contribution of both terrestrial- and marine-derived organic matter (Fig. 2). In contrast, the consumers in Namdae stream showed a relatively narrow range in $\delta^{13} \mathrm{C}$ values (-24.0\% to $-18.0 \%$ in June; $-26.5 \%$ to $-22.1 \%$ in August) compared with other streams, suggesting an important contribution of benthic production and/or marine-derived organic matter (Fig. 2). At all sites, most consumers in August had narrower and more depleted $\delta^{13} \mathrm{C}$ ranges compared to those in June, suggesting an increased contribution of terrestrial-derived organic matter due to the summer monsoon effect created by heavy rainfall (Fig. 2). The $\delta^{15} \mathrm{~N}$ values for most consumers have shown wide ranges at the all sites during both periods, suggesting that there was a stepwise trophic enrichment in $\delta^{15} \mathrm{~N}$ with increasing trophic level from invertebrate to fish consumers (Fig. 3).
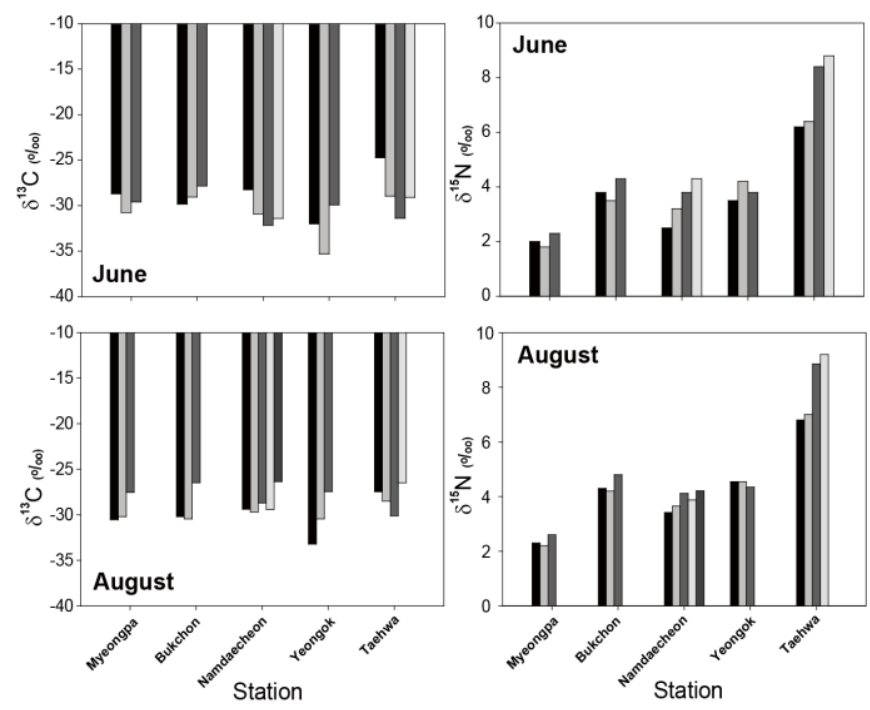

Fig. 2. $\delta^{13} \mathrm{C}$ and $\delta^{15} \mathrm{~N}$ values of suspended particulate organic matter (SPOM) sampled at the five stations during June and August 2017.
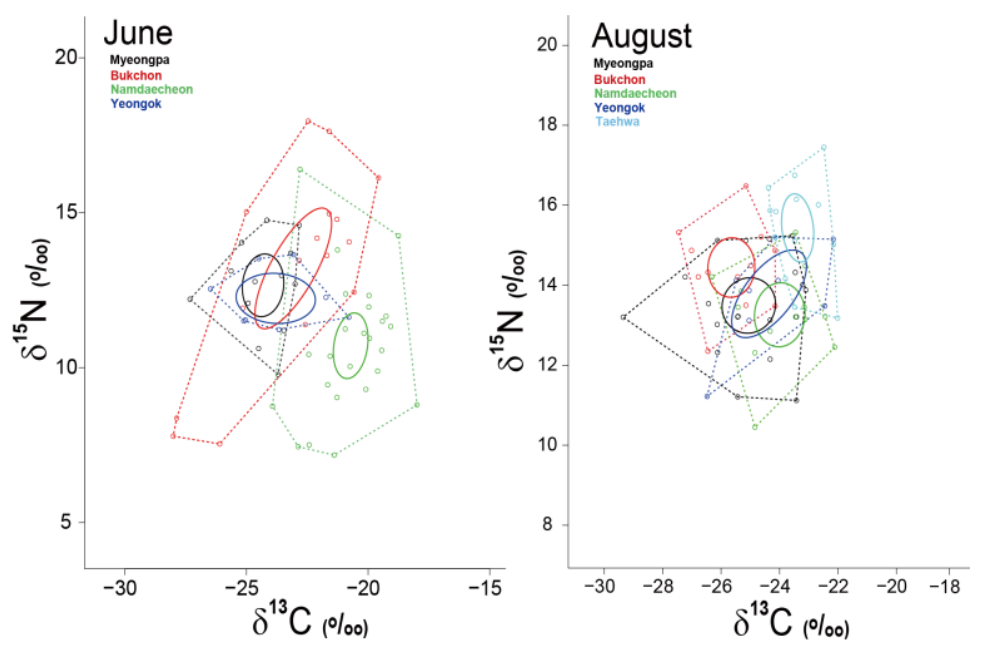

Fig. 3. Bi-plots of the $\delta^{13} \mathrm{C}$ and $\delta^{15} \mathrm{~N}$ values for consumers (circles) at the sampling sites during two periods (June and August 2017). Isotopic niche areas of consumers at the sites during the periods, estimated as the total area (TA, dotted line) and standard ellipse area (SEAc, solid line). 
Among the rivers studied, Namdaecheon, the major releasing and returning area for chum salmon has relatively good status, especially with regards to biological condition (i.e., prey, predator, competition species) when compared with the other rivers. Whereas in the Taehwa River, prey competition for chum salmon with animals that belong to the same trophic level seems to be relatively strong; consequently, prey selection of chum salmon may be restricted. The results from this study will contribute to future research, which seeks to determine the best habitat for returning chum salmon, and better predict the release/survival mechanisms of juvenile salmon in Korean river systems. 